\title{
Prototipe Aplikasi Analisis Butir Soal Ujian Akhir Semester Genap Mata Kuliah Konsep Dasar Pelayanan Asuhan Kesehatan Gigi Dan Mulut Tahun Akademik 2018/2019 Berdasarkan Validitas, Reliabilitas, Daya Pembeda, Tingkat Kesukaran, Dan Efektivitas Pengecoh
}

\author{
Sulur Joyo Sukendro ${ }^{1}$, Tri Wiyatini ${ }^{2}$, Rizal Ginanjar ${ }^{3}$, Yodong $^{4}$
}

\begin{abstract}
ABSTRAK
Tujuan pendidikan adalah mengubah perilaku menjadi yang lebih baik. Dosen melaksanakan proses perkuliahan kepada peserta didik wajib menguasai evaluasi perkuliahan. Kegiatan perkuliahan di Jurusan Keperawatan Gigi Poltekkes Semarang sudah berjalan dengan baik namun masih kurang dalam hal evaluasi terhadap butir-butir soal. Sudah ada e-lerning dengan alamat http://poltekkes-smg.ac.id/helti namun belum didayagunakan secara maksimal oleh para dosen termasuk pengelolaan soal dan diharapkan ada inegrasi dengan https://www.sims-nakes.org.

Jenis penelitian yang akan dilakukan adalah penelitian kualitatif. Metode kualitatif digunakan untuk melakukan proses identifikasi pada tahapan studi pendahuluan yang pada akhirnya terbentuk suatu rancangan Prototipe Aplikasi Analisis Butir Soal Ujian Akhir Semester. Populasi penelitian seluruh mahasiswa semester II Jurusan Keperawatan Gigi Poltekkes Kemenkes Semarang berjumlah 42 orang. Metode waterfall digunakan sebagai proses membangun sistem meliputi analisa kebutuhan, desain sistem, peni;isan kode program, pengujian program, penerapan program dan pemeliharaan. Rancangan sistem menggunakan bahasa pemrograman PHP dan Java - Jquery dengan basis data menggunakan $M y S Q L$.

Telah dibuat Prototipe Aplikasi Analisis Butir Soal Ujian Akhir Semester Genap Mata Kuliah Konsep Dasar Pelayanan Asuhan Kesehatan Gigi Dan Mulut Tahun Akademik 2018/2019 Berdasarkan Validitas, Reliabilitas, Daya Pembeda, Tingkat Kesukaran, Dan Efektivitas Pengecoh. Prototipe ini dibuat agar memudahkan dosen dalam melakukan analisis butir soal ujian pada mahasiswa. Dengan metode ini maka ujian dapat dilakukan berbasi komputer serta paper less.
\end{abstract}

Kata kunci : Analisis, Butir, Soal. 


\begin{abstract}
Aims of education is to change behavior for the better. Lecturers carry out the lecture process to students must master the lecture evaluation. Lecturing activities in the Department of Dental Nursing Poltekkes Semarang has been going well but still lacking in terms of evaluation of the items. There is already an e-lerning address: http://poltekkes-smg.ac.id/helti but it has not been maximally utilized by the lecturers including question management and hopefully integration with https://www.sims-nakes.org.

The research to be conducted is qualitative research. The qualitative method is used to carry out the identification process at the preliminary study stage, which in the end forms a prototype application for the Analysis of the Final Examination. Population of all semester II students of the Dental Nursing Department of the Health Ministry of Semarang was 42 people. The waterfall method is used as the process of building a system including requirements analysis, system design, program code filling, program testing, program implementation and maintenance. The system design uses the programming languages PHP and Java - Jquery with a database using MySQL.

Prototype Application of Item Analysis of Final Examination for Subjects Konsep Dasar Pelayanan Asuhan Kesehatan Gigi dan Mulut 2018/2019 on Validity, Reliability, Distinguishing Power, Difficulty Level, and Effectiveness of Deceivers. This prototype was made to facilitate lecturers in analyzing exam items on students. With this method, the exam can be done on a computer and paper less.
\end{abstract}

Keywords: Analysis, Item, Question.

${ }^{1,2,4}$ :DosenJurusanKeperawatan Gigi PoliteknikKesehatanKemenkes Semarang
${ }^{3}$ :Ketua Unit IT DirektoratPoliteknikKesehatanKemenkes Semarang 


\section{PENDAHULUAN}

Tujuan pendidikan adalah mengubah peserta didik yang meliputi, cara berfikir, merasa, berbuat, dan tingkah laku, jadi dapat dikatakan bahwa tujuan pendidikan adalah mengubah perilaku menjadi yang lebih baik. Pendidikan dan pengajaran adalah salah satu usaha yang bersifat sadar tujuan yang sistematis terarah pada perubahan tingkah laku peserta didik menjadi yang lebih baik. Kemudian pengajaran adalah proses untuk membimbing peserta didik dalam kehidupan untuk mengembangkan diri sesuai dengan tugas perkembangan yang harus dijalani oleh peserta didik tersebut (Undang-Undang Republik Indonesia, 2003).

Pada dunia pendidikan, yang sangat berperan dalam proses pendidikan dan pengajaran adalah dosen. Karena dosen yang melaksanakan proses perkuliahan kepada peserta didiknya, maka salah satu kompetensi yang wajib dikuasai oleh dosen adalah evaluasi perkuliahan. Menurut Sudjana (2013) tes sebagai alat penilaian adalah pertanyaan-pertanyaan yang diberikan kepada mahasiswa untuk mendapat jawaban dari mahasiswa dalam bentuk lisan (tes lisan), dalam bentuk tulisan (tes tulisan), atau dalam bentuk perbuatan (tes tindakan). Menurut Arikunto (2013) tes yang baik adalah yang memenuhi beberapa persyaratan tes yaitu validitas, reliabilitas, objektivitas, praktikabilitas dan ekonomis.

Jurusan Keperawatan Gigi Politeknik Kesehatan Kemenkes (Poltekkes) Semarang beralamat di Jalan Tirto Agung, Pedalangan, Banyumanik, Kota Semarang. Berdasarkan hasil observasi yang telah dilakukan pada tanggal 25-28 Pebruari 2019 dapat diperoleh informasi bahwa kegiatanperkuliahan di Jurusan Keperawatan Gigi Poltekkes Semarangsudahberjalandengan sangatbaik. Evaluasi yang selamainidilaksanakansudah baik akan tetapi belumdilakukan secara rutin penilaianterhadapbutir-butirsoal, sehinggakualitasbutirsoalbelumdiketahuiap akahsoaltersebutsudahmemenuhikriteriates yang baik ataubelum. Sudah ada e-lerning dengan alamat http://poltekkessmg.ac.id/helti namun belum didayagunakan secara maksimal oleh para dosen termasuk pengelolaan soal. Dosen diminta membuat soal ujian akhir semester dalam bentuk kasus/vignet, dimana soal ini diharapkan selanjutnya dapat dikirim ke https://www.sims-nakes.org/ sebagai masukan bank soal uji kompetensi tenaga kesehatan tingkat nasional. Pengelompokan jenis soal pada bank soal uji kompetensi tenaga kesehatan saat ini bukan berdasarkan mata kuliah tetapi kompetensi calon tenaga kesehatan yang akan di uji. 
Menurut Daryanto (2012) analisis butir soal adalah suatu prosedur sistematis, yang akan memberikan informasi-informasi yang sangat khusus terhadap butir tes yang kita susun. Analisis butir soal tes dilakukan bertujuan untuk mendapatkan informasi penting yang berguna untuk evaluasi hasil perkuliahan mahasiswa. Menurut Sudjana (2013) analisis butir soal atau analisis item adalah pengkajian pertanyaanpertanyaan tes agar diperoleh perangkat pertanyaan yang memiliki kualitas yang memadai. Dari pemaparan para ahli, dapat disimpulkan bahwa analisis butir soal adalah suatu prosedur sistematis berupa mengkaji pertanyaan agar diperoleh pertanyaan-pertanyaan yang berkualitas. Analisis butir soal pada dasarnya bertujuan untuk mengetahui apakah setiap item soal benar-benar baik, sehingga diperlukan analisis terhadapnya.

1. Validitas

Menurut Purwanto (2013) validitas (kesahihan) adalah kualitas yang menunjukkan hubungan antara suatu pengukuran (diagnosis) dengan arti atau tujuan kriteria belajar atau tingkah laku. Supranata (2005) menyatakan "validitas adalah suatu konsep yang berkaitan dengan sejauh mana tes telah mengukur apa yang seharusnya diukur". Validitas dibagi menjadi empat bentuk, yaitu:

a. Validitas isi

Validitas isi bertujuan untuk mengetahui sejauh mana peserta didik menguasai materi pelajaran yang telah disampaikan setelah mengalami proses perkuliahan tertentu. Jika keseluruhan soal nampak mengukur apa yang seharusnya tes itu digunakan, tidak diragukan lagi bahwa validitas isi sudah terpenuhi.

b. Validitas konstruk

Validitas konstruk mengandung arti bahwa suatu alat ukur dikatakan valid apabila telah cocok dengan kontribusi teoritik di mana tes itu dibuat.

c. Validitas prediksi

Validitas prediksi bermaksud melihat bagaimana suatu tes dapat memperkirakan perilaku peserta didik pada masa yang akan datang.

d. Validitas konkuren

Validitas konkuren menunjuk pada hubungan antara tes skor yang dicapai dengan keadaan sekarang. Sebuah tes dikatakan memiliki validitas konkuren apabila hasilnya sesuai dengan pengalaman. 
Menurut Sudijono (2012), teknik pengujian validitas item tes hasil belajar dapat menggunakan rumus :

$$
\mathrm{r}_{\mathrm{pbi}}=1+\frac{\mathrm{M}_{\mathrm{p}}-\mathrm{M}_{\mathrm{t}}}{\mathrm{SD}_{t}} \frac{p}{q}
$$

Keterangan :

$$
\begin{aligned}
& \mathrm{R}_{\mathrm{pbi}}=\text { koefisien korelasi point } \\
& \text { biserial yang } \\
& \text { melambangkan kekuatan } \\
& \text { korelasi antara variabel I } \\
& \text { dengan variabel II, yang } \\
& \text { dalam hal ini dianggap } \\
& \text { sebagai Koefisien } \\
& \text { Validitas Item. } \\
& \mathrm{M}_{\mathrm{p}} \quad=\text { Skor rata-rata hitung } \\
& \text { yang dimiliki oleh } \\
& \text { peserta tes yang untuk } \\
& \text { butir item soal telah } \\
& \text { dijawab dengan benar. } \\
& \mathrm{M}_{\mathrm{t}} \quad=\text { Skor rata-rata dari skor }
\end{aligned}
$$

Butir soal dikatakan valid atau tidak valid dapat dilihat dari hasil perhitungan yang dibandingkan dengan $r$ tabel pada taraf signifikansi $5 \%$ sesuai jumlah siswa yang diteliti. Apabila $r_{p b i}>r$ tabel maka butir soal tersebut valid.

\section{Reliabilitas}

Reliabilitas adalah tingkat atau derajat konsistensi dari suatu instrumen. Reliabilitas tes berkenaan dengan pertanyaan, apakah suatu tes diteliti dan dapat dipercaya sesuai dengan kriteria yang telah ditetapkan (Arifin, 2013). Reliabilitas sebuah soal perlu karena sebagai penyokong terbentuknya validitas butir soal sehingga sebuah soal yang valid biasanya reliabel. Sedangkan soal yang reliabel belum tentu valid.

Menurut Arikunto (2013) untuk mencari reliabilitas tes bentuk objektif dapat dilakukan dengan menggunakan rumus:

$$
\mathrm{r}_{11}=\frac{n}{n-1}+\frac{s^{\alpha}-p q}{s^{a}}
$$

Keterangan :

$$
\begin{array}{ll}
\mathrm{r}_{11} & =\text { reliabilitas tes secara } \\
& \text { keseluruhan } \\
\mathrm{p} & =\text { proporsi subjek yang } \\
& \text { menjawab item dengan benar } \\
\mathrm{q} & =\text { proporsi subjek yang } \\
& \text { menjawab salah } \\
\mathrm{pq}= & \text { jumlah hasil perkalian } \mathrm{p} \text { dan } \\
\mathrm{q} & \\
\mathrm{n} \quad=\text { banyaknya item } \\
\mathrm{s} \quad=\text { standar deviasi tes }
\end{array}
$$


3. Tingkat Kesukaran

Perhitungan tingkat kesukaran soal adalah pengukuranseberapa besar derajat kesukaran suatu soal. Soal yang baik adalahsoal yang tidak terlalu mudah atau tidak terlalu sukar. Soal yangterlalu mudah tidak merangsang mahasiswa untuk mempertinggi

usahamemecahkannya. Sebaliknya soal yang terlalu sukar akanmenyebabkan mahasiswa menjadi putus asa dan tidak mempunyaisemangat untuk mencoba lagi karena di luar jangkauannya. Bilangan yang menunjukkan sukar dan mudahnya sesuatusoal disebut indeks kesukaran. Besarnya indeks kesukaran antara0,00 sampai dengan 1,0. Indeks kesukaran ini menunjukkan taraf kesukaran soal. Soal dengan indeks 0,0 menunjukkan bahwa soal itu terlalu sukar, sebaliknya indeks 1,0 menunjukkan bahwa soalnya terlalu mudah.

Menurut Sudijono (2012) rumus untuk mencari angka indek kesukaran

$$
P=\frac{N p}{N}
$$

Keterangan :

$\mathrm{P}=$ proporsi (angka indek kesukaran butir soal)
$\mathrm{N}_{\mathrm{p}}=$ banyaknya peserta tes yang dapat menjawab butir soal dengan benar. $\mathrm{N}$ = jumlah peserta yang mengikuti tes hasil belajar.

\section{Daya Pembeda Soal}

Daya Pembeda Soal menurut Sukiman (2012) adalahkemampuan suatu soal untuk membedakan antara mahasiswa yang mampu (menguasai materi yang ditanyakan) dan mahasiswa yang kurang mampu (belum menguasai materi yang ditanyakan). Daya pembeda soal dapat diketahui dengan melihat besar kecilnya angka Indeks DayaPembeda (IDP).

Daya pembeda dapat diketahui dengan angka indek diskriminasi yang menunjukkan besar kecilnya daya pembeda yang dimiliki oleh butir soal.

Menurut Arifin (2013) rumus untuk menghitung daya pembeda :

$$
\mathrm{D}=\mathrm{P}_{\mathrm{A}}-\mathrm{P}_{\mathrm{B}}
$$

Keterangan :

$\mathrm{D}=$ angka indeks diskriminasi

$\mathrm{P}_{\mathrm{A}}=$ proporsi peserta kelompok atas menjawab benar

$\mathrm{P}_{\mathrm{B}}=$ proporsi peserta kelompok bawah menjawab benar 
Perhitungan indeks daya pembeda dapat disimpulkan dengan acuan sebagai berikut :

$\mathrm{D}: 0,00-0,20:$ jelek (poor)

D : $0,21 \quad-\quad 0,40 \quad$ : cukup

(satisfactory)

D : 0,41-0,70 : baik (good)

D : 0,71 - 1,00 : baik sekali

(excellent)

D : negatif, semuanya tidak baik.

\section{Analisis Pengecoh}

Pada soal bentuk pilihan ganda ada alternatif jawaban (opsi)yang merupakan pengecoh. Butir soal yang baik, pengecohnya akan dipilih secara merata oleh peserta didik yang menjawab salah.Fungsi pengecoh berlaku pada soal pilihan ganda. Di antara pilihan jawaban yang ada, hanya satu yang benar. Selain jawaban yang benar tersebut, ada jawaban yang salah. Jawaban yang salah itulah yang dikenal dengan distractor (pengecoh). Tujuan utama dari pemasangan distractor pada setiap butir item adalah agar dari sekian banyak peserta tes yang mengikuti tes hasil belajar ada yang tertarik untuk memilihnya. Distractor akan mengecoh peserta didik yang kurang mampu untuk dapat dibedakan dengan yang mampu. Distractor yang baik adalah yang dapat dihindari oleh peserta didik yang pandai dan akan dipilih oleh peserta didik yang kurang pandai.

Menurut Arifin (2013) efektivitas pengecoh dapat diukur menggunakan rumus :

$$
I P=\frac{P}{\frac{N-B}{(n-1)}} \times 100 \%
$$

Keterangan :

IP $=$ indeks pengecoh.

$\mathrm{P}=$ jumlah peserta didik yang memilih pengecoh.

$\mathrm{N}=$ jumlah peserta didik yang ikut tes.

$\mathrm{B}=$ jumlah peserta didik yang menjawab benar.

$\mathrm{n}=$ jumlah alternatif jawaban.

1 = bilangan tetap

Sudijono (2012) mengungkapkan bahwa distractor menjalankan fungsinya dengan baik apabila distractor tersebut telah dipilih sekurang-kurangnya $5 \%$ dari seluruh peserta tes. Distractor yang telah menjalankan fungsinya dengan baik dapat digunakan kembali pada tes yang akan datan

6 Mata Kuliah Konsep Dasar Pelayanan Asuhan Kesehatan Gigi dan Mulut

Menurut Gultom dan Laut (2018), Mata kuliahKonsep Dasar 
Pelayanan Asuhan Kesehatan Gigi dan Mulutmenguraikantentang proses keperawatangigi yang didasarkan pada teoriDental Hygiene yang meliputipengkajian, diagnosis, perencanaan, implementasisertaevaluasiasuhanke perawatangigi dan mulut yang diterapkandenganberbagaikasus pada sasaranindividu (pasien) di klinik.

Pembelajarandilakukandenganmeto deceramah, diskusi dan praktikum di

klinik.

Materiinidiberikansetelahmahasiswa menyelesaikanmatakuliahKonsep

Dasar PelayananAsuhanKesehatan

Gigi dan Mulut I.

Menurut Gultom dan Laut (2018), Kompetensiumum Mata KuliahKonsep Dasar Pelayanan Asuhan Kesehatan Gigi dan Mulut, mahasiswadiharapkanmampumenye lesaikanasuhankesehatangigi dan mulutindividumeliputiupayapeningk atankesehatangigi dan mulut, upayapencegahanpenyakitgigi, dan pelayanankesehatandasar pada kasuskesehatangigiterbatas.Kompet ensikhususMata KuliahKonsep Dasar Pelayanan Asuhan Kesehatan Gigi dan Mulut, mahasiswadiharapkanmampu ;

a). Menjelaskan konsep pelayanan asuhan kesehatan gigi dan mulut

b). Menjelaskan proses pelayanan asuhan kesehatan gigi dan mulut

c). Menjelaskan tahap pengkajian pelayanan asuhan kesehatan gigi dan mulut

d). Menjelaskan tahap diagnosis pelayanan asuhan kesehatan gigi dan mulut

e). Menjelaskan tahap perencanaan pelayanan asuhan kesehatan gigi dan mulut

f). Menjelaskan tahap tindakan pelayanan asuhan kesehatan gigi dan mulut

g). Menjelaskan tahap evaluasi pelayanan asuhan kesehatan gigi dan mulut

h). Menjelaskan dokumentasipelayanan asuhan kesehatan gigi dan mulut

i). Melakukan pemeriksaan subyektif dan obyektif pada pasien individu

j). Merumuskan diagnosis keperawatan gigi pasien individu

k). Menyusun kembali rumusan diagnosis keperawatan gigi pasien 
1). Menetapkan rencana perawatan pasien

m). Menyusun rencana perawatan pasien

n). Melaksanakan tindakan promotif penyuluhan dengan cara chair side talk

o). Membimbing tindakan promotif cara menyikat gigi yang benar

p). Mengerjakan tindakan preventif berupa scaling

q). Mengerjakan tindakan preventif berupa fissure sealant

r). Mengerjakan tindakan preventif berupa pemberian Casein PhosphopeptideAmorphous Calcium Phosphate (CPP-ACP)

s). Mengerjakan tindakan preventif berupa aplikasi fluor

t). Mengerjakan penambalan Atraumatic Restorative Treatment/ART

u). Mengerjakan tindakan kuratif konservasi berupa penambalan 1 bidang

v). Mengerjakan penambalan gigi dengan 2 bidang

w). Mengerjakan pencabutan gigi dengan surfaceanesthesia

x). Mengerjakan pencabutan gigi dengan infiltrasi anestesi

y). Melaksanakan rujukan pada kasus-kasus yang bukan merupakan kompetensi

z). Menyelesaikan evaluasi asuhan keperawatan gigi dan mulut pasien

a). Menyusun dokumentasi pelayanan asuhan kesehatan gigi dan mulut

7. Metode pengembangan Sistem Waterfall

Metode waterfall merupakanmetode digunakanuntuk membangun sistem aplikasi analisis butir soal. Metode waterfall dilakukansecarabe rurutanatausecara linear. Jadijikalangkah ke-1 belumdikerjakan, makalangkah 2 tidakdapatdikerjakan. Jikalangkah ke-2 belumdikerjakanmakalangkah ke-3 juga tidakdapatdikerjakan, begituseterusnya.

Secaraotomatislangkah ke-3 akanbisadilakukanjikalangkah ke-1 dan ke-2 sudah dilakukan.

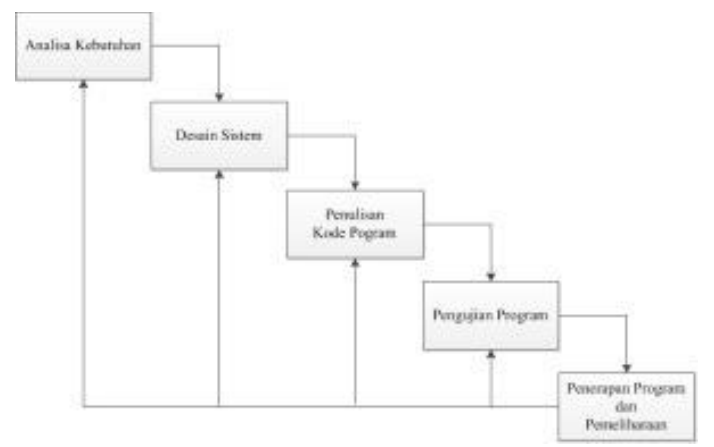


Gambar 1. Tahapan membangun sistem dengan metode waterfall Secaragarisbesarmetode waterfall $\mathrm{m}$ empunyailangkah-

langkahsebagaiberikut

(Kadir, 2003):

a. Analisa

Kebutuhan:Langkahinimerupak ananalisaterhadapkebutuhansist em. Pengumpulan data dalamtahapinibisamelakukanse buahpenelitian, wawancaraataustudiliteratur.

Sistemanalisakanmenggaliinfor masisebanyak-

banyaknyadari user sehinggaak anterciptasebuahsistemkompute $r$ yang bisamelakukantugastugas yang diinginkan oleh user tersebut.

Tahapaniniakanmenghasilkand okumen user

requirment ataubisadikatakanse bagai data yang berhubungandengankeinginan $u$ ser dalampembuatansistem.

Dokumeninilah yang akanmenjadiacuansistemanalisu ntukmenerjemahkankedalamba hasapemrogram.

b. DesainSistem

:Tahapandimanadilakukanpenu anganpikiran dan perancangansistemterhadapsolu sidaripermasalahan yang adadenganmenggunakanperang katpemodelansistemseperti diagram alir data (data flow diagram), diagram hubunganentitas (entity relationship diagram) sertastruktur dan bahasan data.

c. PenulisanKodeProgram :Penulisankode program atau coding merupakanpenerje mahan design dalambahasa yang bisadikenali oleh komputer. Dilakukan

oleh programmer yang akanmeterjemahkantransaksi yang diminta oleh user. Tahapaninilah yang merupakantahapansecaranyatad alammengerjakansuatusistem.

Dalamartianpenggunaankomput erakandimaksimalkandalamtah apanini. Setelah pengkodeanselesaimakaakandil akukan testing terhadapsistem yang telahdibuattadi. Tujuan testing adalahmenemuk ankesalahan-

kesalahanterhadapsistemtersebu $\mathrm{t}$ dan kemudianbisadiperbaiki.

d. PengujianProgram

:Tahapanakhirdimanasistem yang barudiujikemampuan dan keefektifannyasehinggadidapat 
kankekurangan

kelemahansistem

yang

kemudiandilakukanpengkajianu

lang

dan

perbaikanterhadapaplikasimenj

adilebihbaik dan sempurna.

e. Penerapan Program dan

Pemeliharaan :Perangkatlunak yang

sudahdisampaikankepadapelan

gganpastiakanmengalamiperub

ahan.

Perubahantersebutbisakarenam

engalamikesalahankarenaperan

gkatlunakharusmenyesuaikande

nganlingkungan

(periperalatausistemoperasibaru )

baru,

ataukarenausermembutuhkanpe

rkembanganfungsional.

\section{METODEPENELITIAN}

Variabel penelitian dalam pembuatan Prototipe Aplikasi Analisis Butir Soal Ujian Akhir Semester Genap Mata Kuliah Konsep Dasar Pelayanan Asuhan Kesehatan Gigi Dan Mulut Tahun Akademik 2018/2019 Berdasarkan Validitas, Reliabilitas, Daya Pembeda, Tingkat Kesukaran, Dan Efektivitas Pengecoh meliputi aspek-aspek : analisa kebutuhan, desain sistem, penulisan kode program, pengujian program, penerapan program dan pemeliharaan.
Jenis penelitian yang akan dilakukan adalah penelitian kualitatif. Metode kualitatif pada penelitian ini digunakan untuk melakukan proses identifikasi pada tahapan studi pendahuluan dalam metodologi pengembangan sistem yang pada akhirnya terbentuk suatu rancangan Prototipe Aplikasi Analisis Butir Soal Ujian Akhir Semester.

Waktu pengumpulan data yang digunakan adalah sebelum dan sesudah perlakuan / uji coba software yaitu 10 Juni 2019 sampai dengan 18 Oktober 2019. Subjek yang diamati adalah 60 orang mahasiswa semester II Program Studi DIV Keperawatan Gigi Jurusan Kesehatan Gigi Politeknik Kesehatan Kemenkes Semarang. Instrumen penelitian yang digunakan pada penelitian ini Kuesioner studi pendahuluan, Check list tentang kualitas informasi.

Alur penelitian pembuatan prototipe software sistem Prototipe Aplikasi Analisis Butir Soal Ujian Akhir Semester akan mengikuti tahapan sesuai dengan metodewaterfallmeliputi analisa kebutuhan, desain sistem, peni;isan kode program, pengujian program, penerapan program dan pemeliharaan.

\section{HASIL DAN PEMBAHASAN}

Prototipe Aplikasi Analisis Butir Soal memiliki menu utama sebagai berikut: 
a. Menu untuk Dosen meliputi :

Dasboard, Struktur kurikulum,

Data Peserta, Manajemen Soal, Manajemen Ujian, Laporan.

b. Menu untuk mahasiswa meliputi : profil peserta, jadwal ujian

Hasil Analisa butir soal

Hasil jawabanrespondendari Prototipe Aplikasi Analisis Butir Soal Ujian Akhir Semester Genap Mata Kuliah Konsep Dasar Pelayanan Asuhan Kesehatan Gigi Dan Mulut II Tahun Akademik 2018/2019 Berdasarkan Validitas, Reliabilitas, Daya Pembeda, Tingkat Kesukaran, dan Efektivitas Pengecoh meliputi aspek-aspek tentang kualitas informasi, diantaranyaadalahsebagaiberikut:

a. Hasil ujian dapat langsung diperoleh setelah selesai ujian baik dalam bentuk tampilan maupun file yang dapat diunduh.

b. Hasil analisis butir soal berdasarkan hasil tingkat kesukaran

Kategori Soal $0,00-0,30$ soal tergolong sukar 0,31 - 0,70 soal tergolong sedang 0,71 - 1,00 soal tergolong mudah c. Hasil analisis butir soal berdasarkan hasil daya pembeda

Kategori Soal 0,40 - 1,00 soal diterima baik 0,30 - 0,39 soal diterima tetapi perlu diperbankeister gasal Mata Kuliah Konsep

0,20-0,29 soal diperbaiki

$0,19-0,00$ soal tidak dipakai/dibuang

d. Hasil analisis butir soal berdasarkan kualitas pengecoh hanya 5 soal yang perlu diperbaiki.

e. Hasil analisis butir soal berdasarkan uji validitas pada 34 butir soal pilihan ganda dari 42 mahasiswa dapat dilihat pada kolom keterangan valid atau tidak valid. Pada kolom keterangan terlihat 33 soal hampir semua pertanyaan instrument tidak valid.

f. Hasil analisis butir soal berdasarkan uji reliabilitas dari 42 mahasiswa adalah terlihat 33 soal reliabiltas rendah.

Prototipe Aplikasi Analisis Butir Soal Ujian Akhir Semester Genap Mata Kuliah Konsep Dasar Pelayanan Asuhan Kesehatan Gigi Dan Mulut II Tahun Akademik 2018/2019 Berdasarkan Validitas, Reliabilitas, Daya Pembeda, Tingkat Kesukaran, dan Efektivitas Pengecoh dibuat agar memudahkan dosen dalam melakukan analisis butir \$al ujian pada mahasiswa. Dengan̂ metode ini maka ujian dapat dilakukan berbasi komputer serta paper less. Adapun dari hasil analisa $2^{\text {soal ujian akhir }}$ 
Dasar Pelayanan Asuhan Kesehatan Gigi Dan Mulut IITahun Akademik 2018/2019 adalah sebagai berikut :

a. Validitas

Validitas soal ujian akhir semester gasal Mata Kuliah Konsep Dasar Pelayanan Asuhan Kesehatan Gigi Dan Mulut IITahun Akademik 2018/2019diuji melalui pengujian secara rasional (logis) dan dari segi item atau butir soal. Secara rasional validitas soal dilihat dari segi kesesuaian isi soal dengan materi pelajaran dan indikatornya. Dari hasil analisis validitas logis, soal ujian akhir semester gasal Mata Kuliah Konsep Dasar Pelayanan Asuhan Kesehatan Gigi Dan Mulut II telah valid karena isi soal telah sesuai dengan materi yang dipelajari di semester II dan sesuai dengan indikatornya.

Dilihat dari segi item soal, validitas butir soal Ujian Akhir Semester Gasal Mata Kuliah Konsep Dasar Pelayanan Asuhan Kesehatan Gigi Dan Mulut II dihitung dengan menggunakan rumus Indeks Point Biserial (rpbi) dengan taraf signifikansi $5 \% \quad(0,217)$. Jika rhitung > rtabel maka butir soal dikatakan valid.

Berdasarkan hasil analisis, pada soal UAS Mata Kuliah Konsep
Dasar Pelayanan Asuhan Kesehatan Gigi Dan Mulut II terdapat 12 soal valid atau sekitar $35 \%$ dari keseluruhan soal dan butir soal yang tidak valid berjumlah 22 butir soal atau $64 \%$. Dari penjelasan tersebut dapat disimpulkan jika soal termasuk soal yang berkualitas kurang baik dari segi validitasnya karena jumlah butir soal yang valid kurang dari $50 \%$ keseluruhan soal. Dapat dikatakan soal UAS Mata Kuliah Konsep Dasar Pelayanan Asuhan Kesehatan Gigi Dan Mulut II belum dapat mengukur apa yang seharusnya diukur. Menurut Sudijono (2012), validitas item dari suatu tes adalah ketepatan mengukur yang dimiliki dalam mengukur apa yang seharusnya diukur lewat butir item tersebut." Berdasarkan hasil analisis validitas butir soal dapat ditindaklanjuti sebagai berikut :

1).Butir soal yang valid dapat disimpan di bank soal dan dapat digunakan kembali pada tes hasil belajar yang akan datang.

2). Butir soal yang tidak valid diperbaiki dengan disesuaikan indikator dan meningkatkan 
penguasaan teknik tentang penyusunan butir soal.

b. Reliabilitas

Reliabilitas soal UAS Mata Kuliah

Konsep Dasar Pelayanan Asuhan Kesehatan Gigi Dan Mulut II dihitung dengan menggunakan rumus KR20. Pemberian interpretasi terhadap koefisien reliabilitas tes (r11) menggunakan patokan apabila R11 sama dengan atau lebih besar dari 0,70 maka tes hasil belajar yang sedang diuji dinyatakan reliabel. Namun jika R11 kurang dari 0,70 maka dapat dinyatakan tidak reliabel. Berdasarkan perhitungan yang dilakukan diperoleh hasil r11= 0,31 . Hasil perhitungan tersebut menunjukkan bahwa soal UAS Mata Kuliah Konsep Dasar Pelayanan Asuhan Kesehatan Gigi Dan Mulut II memiliki reliabilitas yang rendah karena r11 $\leq 0,70$. Suatu tes dikatakan reliabel jika selalu memberikan hasil yang sama bila diteskan pada kelompok yang sama pada waktu oleh subjek yang berbeda (Arifin, 2013). Dari penjelasan diatas dapat disimpulkan bahwa soal UAS Mata Kuliah Konsep Dasar Pelayanan Asuhan Kesehatan Gigi Dan Mulut
II merupakan soal yang berkualitas kurang baik dari segi reliabilitasnya.

c. Daya Pembeda

Daya pembeda soal UAS Mata Kuliah Konsep Dasar Pelayanan Asuhan Kesehatan Gigi Dan Mulut II dihitung menggunakan aplikasi analisis butir soal dengan menggunakan rumus Daya Pembeda. Daya pembeda setiap butir soal dihitung dengan menghitung selisih proporsi peserta kelompok atas yang menjawab benar (PA) dengan proporsi peserta kelompok bawah yang menjawab benar (PB). Dalam melakukan interpretasi terhadap hasil perhitungan daya pembeda dapat digunakan kriteria sebagai berikut :

D : 0,00 - 0,20 : jelek (poor)

D : 0,21 - 0,40 : cukup

(satisfactory)

D : 0,41 - 0,70 : baik (good)

D : $0,71-1,00$ : baik sekali (excellent)

D : negatif, semuanya tidak baik.

Jadi semua butir soal yang mempunyai nilai $\mathrm{D}$ negatif sebaiknya dibuang saja. (Suharsimi Arikunto, 2013)

Berdasarkan hasil analisis, butir soal yang memiliki daya pembeda jelek berjumlah 11 butir, butir soal 
yang memiliki daya pembeda

cukup berjumlah 6 butir, butir soal yang memiliki daya pembeda baik berjumlah 12 butir.

Arifin (2012) menyatakan bahwa "perhitungan daya pembeda adalah pengukuran sejauh mana suatu butir soal mampu membedakan peserta didik yang sudah menguasai materi dengan peserta didik yang belum/kurang menguasai materi berdasarkan kriteria tertentu. Jadi dapat disimpulkan bahwa soal UAS Mata Kuliah Konsep Dasar Pelayanan Asuhan Kesehatan Gigi Dan Mulut II belum berkualitas dari segi daya pembedanya yang dapat membedakan kelompok atas dan kelompok bawah.

Selanjutnya butir soal yang sudah memiliki daya pembeda baik (cukup, baik, dan sangat baik) sebaiknya dimasukkan dalam bank soal tes hasil belajar, butir soal yang daya pembedanya jelek diperbaiki untuk diajukan lagi dalam tes hasil belajar yang akan datang. Khusus butir soal dengan daya pembeda yang negatif, sebaiknya pada tes hasil belajar yang akan datang tidak usah dikeluarkan lagi, sebab butir soal tersebut kualitasnya sangat jelek.
Ada beberapa faktor kemungkinan yang mempengaruhi daya pembeda rendah, seperti :

1). Kunci jawaban butir soal tidak tepat.

2). Butir soal memiliki 2 atau lebih kunci jawaban yang benar.

3). Kompetensi yang diukur tidak jelas.

4). Pengecoh tidak berfungsi dengan baik.

5). Materi terlalu sulit.

6). Sebagian besar mahasiswa yang memahami materi yang ditanyakan berpikir ada yang salah informasi dalam butir soalnya.

\section{e. Tingkat Kesukaran}

Tingkat kesukaran soal UAS Mata Kuliah Konsep Dasar Pelayanan Asuhan Kesehatan Gigi Dan Mulut II tahun ajaran 2018/2019 dihitung dengan menggunakan rumus indeks kesukaran. Indeks kesukaran setiap butir soal diperoleh dengan membagi banyaknya siswa yang menjawab soal dengan benar dengan jumlah seluruh siswa peserta tes. Hasil perhitungan dari aplikasi kemudian diinterpretasikan menggunakan kriteria sebagai berikut. 
Soal dengan $\mathrm{P}$ 0,00 sampai 0,30

adalah soal sukar

Soal dengan $\mathrm{P}$ 0,31 sampai 0,70

adalah soal sedang

Soal dengan P 0,71 sampai 1,00

adalah soal mudah (Suharsimi

Arikunto, 2013) Berdasarkan hasil

analisis butir yang tergolong sukar

berjumlah 11 butir, butir soal yang

tergolong sedang berjumlah 14

butir, dan butir soal yang tergolong

mudah berjumlah 9 butir.

Suatu soal dianggap baik jika memiliki tingkat kesukaran antara 0,30 - 0,70 (Arikunto. 2013).

Sehingga dapat disimpulkan bahwa soal UAS Mata Kuliah Konsep Dasar Pelayanan Asuhan Kesehatan Gigi Dan Mulut II tahun ajaran 2018/2019 memiliki kualitas baik dilihat dari tingkat kesukaran soal dikarenakan soal yang tergolong sedang berjumlah 14 butir soal dari keseluruhan 34butir soal. Tindak lanjut yang dapat dilakukan setelah analisis tingkat kesukaran butir soal adalah sebagai berikut (Sudijono. 2012)

1). Butir soal yang memiliki tingkat kesukaran dalam kategori baik (derajat kesukarannya sedang), sebaiknya butir soal tersebut disimpan dalam bank soal agar dapat dikeluarkan lagi pada waktu yang akan datang.

2). Butir soal yang termasuk kategori sukar, ada 3 kemungkinan tindak lanjut yaitu:

a) Butir soal tersebut dibuang dan tidak akan dikeluarkan lagi dalam tes hasil belajar yang akan datang.

b) Diteliti ulang sehingga dapat diketahui faktor yang menyebabkan butir item yang bersangkutan sulit dijawab oleh testee. Perbaikan dapat dilakukan dengan menyederhanakan kalimat soal sehingga tidak menimbulkan multitafsir atau mengganti angka pada soal akuntansi. Setelah dilakukan perbaikan, butir soal tersebut dapat dikeluarkan lagi pada tes hasil belajar yang akan datang dengan syarat tetap terjaga kerahasiaannya.

c) Butir soal tetap dipertahankan untuk digunakan lagi pada tes-tes yang sifatnya sangat ketat, dalam arti sebagian besar dari testee tidak akan diluluskan dalam tes seleksi tersebut. 
3). Butir soal yang termasuk kategori mudah, ada 3 kemungkinan tindak lanjut yaitu:

a) Butir soal tersebut dibuang dan tidak akan dikeluarkan lagi di tes hasil belajar yang akan datang.

b) Diteliti ulang untuk mengetahui faktor yang menyebabkan butir soal tersebut dapat dijawab benar oleh hampir seluruh testee. Ada kemungkinan alternatif yang dipasangkan pada butir soal terlalu mudah diketahui oleh testee. Perbaikan dapat dilakukan dengan memperbaiki opsi dan membuat kalimat soal menjadi lebih kompleks. Setelah dilakukan perbaikan, soal dapat dikeluarkan lagi pada tes hasil belajar yang akan datang.

c) Butir soal dipertahankan untuk dimanfaatkan pada tes yang sifatnya longgar, dalam arti sebagian besar testee akan dinyatakan lulus dalam tes seleksi tersebut. Dalam kondisi seperti ini tes hanyalah formalitas saja.
Perhitungan kualitas pengecoh dengan menggunakan program aplikasi analisis butir soal. Pengecoh dapat dikatakan berfungsi dengan baik apabila telah dipilih sekurang-kurangnya $5 \%$ dari seluruh peserta tes. Dalam menginterpretasikan kualitas pengecoh setiap butir soal digunakan kriteria pada skala Likert sebagai berikut :

1). Kualitas pengecoh dikatakan sangat baik apabila keempat jawaban pengecoh berfungsi.

2). Kualitas Pengecoh dikatakan baik apabila terdapat tiga jawaban pengecoh yang berfungsi.

3). Kualitas pengecoh dikatakan cukup baik apabila terdapat dua jawaban pengecoh yang berfungsi.

4). Kualitas pengecoh dikatakan kurang baik apabila terdapat satu jawaban pengecoh yang berfungsi.

5). Kualitas pengecoh dikatakan tidak baik apabila semua jawaban pengecoh tidak berfungsi.

Berdasarkan hasil analisis, hanya 5 dari 34 butir soal berkualitas tidak baik. Tindak lanjut yang dapat 
dilakukan yaitu sebagai berikut

(Sudijono, 2012) :

1). Pengecoh yang telah berfungsi dengan baik dapat dipakai lagi pada tes hasil belajar yang akan datang.

2). Pengecoh yang belum berfungsi dengan baik sebaiknya diperbaiki atau diganti dengan pengecoh yang lain. Cara yang dapat digunakan untuk membuat pengecoh yang baik yaitu sebagai berikut (Surapranata. 2005) :

a) Gunakan pilihan jawaban yang paling umum dimengerti peserta didik.

b) Gunakan kata-kata yang kedengarannya sama.

c) Gunakan yang kira-kira ada kaitannya.

d) Gunakan bahasa buku atau terminologi buku yang tidak diragukan lagi kebenarannya.

\section{KESIMPULAN DAN SARAN}

Kesimpulan dari penelitian ini adalah :

a. Telah tersusun aplikasi analisis butir soal

b. Menyusun panduan penggunaan aplikasi analisis butir.

c. Sosialisasi kepada mahasiswa Program Studi DIV Keperawatan Gigi Jurusan Keperawatan Gigi
Politeknik Kesehatan Kemenkes Semarang untuk mengikuti uji coba.

d. Melakukan ujicoba aplikasi analisis butir tahap II .

e. Bila diperlukan perbaikan hasil ujicoba tahap II.

Saran dari penelitian ini adalah

a. Setelah perbaikan tahap II dilakukan ujicoba pada beberapa mata kuliah dengan bantuan beberapa orang dosen dalam bentuk pengabdian masyarakat di lingkungan kampus JKG Poltekkes Kemenkes Semarang.

b. Perbaikan menu agar dapat digunakan pada beberapa dosen.

c. Integrasi aplikasi analisis butir soal di web e-learning PoltekkesKemenkes Semarang

\section{DAFTAR PUSTAKA}

Arifin, Z., 2013, EvaluasiPembelajaran. Bandung: RemajaRosdakarya.

Arikunto, S., 2013, Dasar-dasarEvaluasi Pendidikan Jilid 2. Jakarta: BumiAksara.

Daryanto. 2012,Evaluasi Pendidikan, Jakarta: RinekaCipta.

Gultom, E., Laut, D.M., 2018, Konsep Dasar PelayananAsuhanKesehatan Gigi dan Mulut, BPPSDMKes, Kemenkes 
Mardapi,D.,

2008,Teknik

PenyusunanInstrumen dan Nontes, Yogyakarta: Mitra Cendikia Offset.

Martono,N.2010,MetodePenelitianKuantit atif, Jakarta: PT Raja GrafindoPersada.

Purwanto. 2013,Evaluasi Hasil Belajar, Yogyakarta :PustakaPelajar

Sudaryono. 2012,DasardasarEvaluasiPembelajaran, Yogyakarta: GrahaIlmu.

Sudijono,A., 2012,PengantarEvaluasi Pendidikan, Jakarta: Raja GrafindoPersada.
Sudjana, N., 2013,Penilaian Hasil Proses BelajarMengajar, Bandung: PT RemajaRosdakarya.

Sukiman. 2012,PengembanganSistemEvaluasi, Yogyakarta: InsanMadani.

Supranata,S., 2005,Panduan PenulisanTesTertulisImplementasiK urikulum2004. Bandung : PT RemajaRosdakarya.

Undang-Undang Republik Indonesia, 2003, Undang-Undang Republik Indonesia, Nomor 20, Tahun 2003, tentang

Pendidikan. 